\title{
Skin Diseases in Human
} Immunodeficiency Virusinfected children in the era of Highly Active Antiretroviral Therapy: Epidemiological and Clinical Profile in Pediatric

\section{Department of Cotonou, Benin}

Keywords: Antiretroviral therapy; HIV; Skin diseases; Children; Benin Summary

Aim: To determine the epidemiological and clinical profile of skin diseases in HIV-infected children followed in Pediatric Department a the University Hospital of Cotonou, Benin.

Method: A 6-month transversal and descriptive study was carried out and included HIV-infected children aged 6 weeks to 15 years, on or no on antiretroviral therapy, followed since 2002 and who were suffering of skin disease. Data collected were analyzed with Epi Info 6 and SPSS 16.

Results: From the 187 children, $61 \%$ (114) had at least a skin disorder. The sex ratio $\mathrm{M} / \mathrm{F}$ was 0.9 and the mean age was 8 years \pm 3.8 years. We diagnosed 240 cutaneous diseases parted into infectious (55 cases, 22.9\%) and non-infectious (185 cases, $77.1 \%$ ). At least two skin diseases were observed in $97.4 \%$ of children. The 240 skin diseases were distributed according to diagnostic and prognostic interest into common (65.5\%), opportunistic $(26.6 \%)$ and iatrogenic $(7.9 \%)$. Immuno-depression was absent or insignificant (CD4 $2350 / \mathrm{ml}$ ) in $82.5 \%$ of children and moderate to severe $(C D 4<350 / \mathrm{ml})$ in $17.5 \%$. Antiretroviral therapy was used in $75.4 \%$ of children.

Conclusion: Highly Active AntiRetroviral Therapies (HAART) have reduced the occurrence of opportunistic dermatosis more than the overall frequency and multiple character of skin diseases in HIV infected infants in the University Hospital of Cotonou.

\section{Introduction}

Dermatological manifestations related to Human Immunodeficiency Virus (HIV) infection are polymorphic and very frequent, found in $60-100 \%$ of children. Their frequency and severity are proportional to the degree of immunosuppression [1-9]

Since the advent of Highly Active Antiretroviral Therapies (HAART) the natural history of dermatological manifestations has been intensely altered. In fact the introduction of these treatments usually leads to spontaneous improvement of most of them especially opportunistic infections. However it can sometimes be accompanied by the appearance of adverse effects or certain dermatoses such as Immune Restoration Syndrome (IRS) [10-15].

\section{Journal of}

\section{Clinical \& Investigative} Dermatology

\begin{abstract}
Adegbidi $\mathrm{H}^{1 *}$, Degboe $\mathrm{B}^{1}$, Akpadjan $\mathrm{F}^{1}$, Akioh I', Atadokpede $\mathrm{F}^{1}$, Kouotou $\mathrm{E}^{2}$, Koudoukpo $\mathrm{C}^{3}$, Almeida $\mathbf{M}^{4}$, Alihonou $\mathrm{F}^{4}$ and BagnanTossa $\mathrm{L}^{4}$

${ }^{\prime}$ Department of Dermatology and Venereology, Faculty of Health Sciences, University of Abomey-Calavi, Cotonou, Benin

${ }^{2}$ Department of Dermatology and venerology, Faculty of Medicine and Biomedical Sciences, University of Yaounde I, Yaounde, Cameroon

${ }^{3}$ Department of Dermatology-Venereology, Faculty of Medicine, University of Parakou, Parakou, Benin

${ }^{4}$ Department of Pediatrics and Medical Genetics, Faculty of Health Sciences, University of Abomey-Calavi, Cotonou, Benin

\section{*Address for Correspondence}

Hugues Adegbidi, Department of Dermatology and Venereology, Faculty of Health Sciences, University of Abomey-Calavi, Cotonou, Benin, Tel: 00229950642 31/ 97192412 03; E-mail: adegbidih@yahoo.fr

Submission: 07 July, 2017

Accepted: 17 August, 2017

Published: 24 August, 2017

Copyright: (c) 2017 Adegbidi $\mathrm{H}$, et al. This is an open access article distributed under the Creative Commons Attribution License, which permits unrestricted use, distribution, and reproduction in any medium, provided the original work is properly cited.
\end{abstract}

Unlike developed countries, most studies in low-income countries have shown an increase in morbidity and mortality, including dermatological manifestations, during the first two years of Anti Retroviral Therapy (ART) especially during the first 6 months. The causes of this phenomenon are often entangled. The main ones are: Advanced immuno-depression at the time of treatment, SRI, severe malnutrition, difficulties in accessing ARVs and poor adherence or ineffective ARVs $[1,3,6]$.

Since the introduction of HAART in developing countries, data on changing the profile of dermatoses in children are almost nonexistent. Therefore in our African context it was appropriate to carry out a study to determine the epidemiological and clinical profile of dermatoses in HIV-infected children, followed in the Pediatrics Department at the University Hospital of Cotonou, Benin.

\section{Methods}

We carried out a transversal and descriptive study over 6 months from February to July 2016 in Pediatrics and Medical Genetics Department at the University Hospital of Cotonou (CNHU-C). It covered the group of children aged 6 weeks to 15 years, HIV-infected 9 under or without ART followed since 2002 (year of introduction of ART multi-therapies in the department) as well as the new patients consulted during the period of study. It also included patients whose diagnosis revealed at least one dermatosis. Infants considered HIVinfected were children whose HIV serum was positive after 18 months and those who had a positive Polymerase Chain Reaction (PCR) before 18 months.

Children were included after written consent from their parents. Data were based on medical records; interrogation and the physical examination were collected using a fact sheet. The variables studied were qualitative and quantitative. 
Citation: Adegbidi H, Degboe B, Akpadjan F, Akioh I, Atadokpede F, et al. Skin Diseases in Human Immunodeficiency Virus-infected children in the era of Highly Active Antiretroviral Therapy: Epidemiological and Clinical Profile in Pediatric Department of Cotonou, Benin. J Clin Investigat Dermatol. 2017;5(2): 5

ISSN: 2373-1044

Epi Info 6 and SPSS 16 were used data analysis and statistical methods. The link between the occurrence of dermatosis and the other independent variables was made by a bi-varied analysis. Pearson chi-square was used to find an association between the variables. The difference was significant when $\mathrm{p}<0.05$. The confidentiality and anonymity in the processing of the data were respected.

\section{Results}

\section{Epidemiological profile}

During the study period out of a total of 187 children infected and monitored in the Pediatrics and Medical Genetics Department at the University Hospital of Cotonou, 114 had at least one dermatosis with a prevalence of $61 \%$. The sex ratio $\mathrm{M} / \mathrm{F}$ in dermatosis-infected children was $0.9(\mathrm{p}=0.2)$.

The mean age was 8 years \pm 3.8 years. In the age group 0 - 4 years $(\mathrm{n}=41)$, the proportion of children with dermatosis was $85.5 \%$ versus 9.5\% for those without dermatosis $(\mathrm{p}=0.003)$. In the 5-9 and 10-15 age groups, the difference was not statistically significant $(\mathrm{p}>0.05)$.

In our series children attending school counted for $71.9 \%$ of cases and $48.2 \%$ were in primary school. Children's mothers with dermatosis had primary level in $43.9 \%$ of cases and $30.7 \%$ were out of school. According to their professional status they were either housewives $(33.3 \%)$ or resellers (31.6\%).

\section{Clinical and immunologic characteristics}

The modes of HIV transmission were vertical (94.7\%) and blood (5.3\%). All children in the series were type HIV1-infected. In the series of 114 children with dermatosis $81.6 \%$ had a history of dermatosis including prurigo (38.7\%) and cutaneous staphylococcal disease (18.3\%).Dermatosis revealed seropositivity in $32.5 \%$ of cases. It occurred before the discovery of seropositivity in $38.5 \%$ of cases and in $24.3 \%$ afterwards.

According to World Health Organization (WHO) classification clinical stages 1, 2, 3 and 4 counted for $28.1 \%, 56.1 \%, 9.7 \%$ and $6.1 \%$ respectively for children with dermatosis. The clinical stage 2 was the most represented $(\mathrm{p}=0.0002)$.

The dermatological status of the 187 children consulted according to the degree of immunosuppression is shown in Table $1: 0.1 \leq p \leq 0.7$. Depending on the degree of immunosuppression there was no significant difference between children who had dermatosis and those who did not. Similarly, the occurrence of dermatosis did not depend on the degree of immunosuppression.

Table 1: Dermatologic status according to the degree of immunosuppression in the 187 HIV-infected children seen in consultation in the SPGM from February to July 2016.

\begin{tabular}{|c|c|c|c|c|c|}
\hline \multicolumn{7}{|c|}{ Degree of immunosuppression - Number of CD4/ mI } \\
\hline & $\begin{array}{c}\text { None - } \\
\begin{array}{c}500 \mathrm{n} \\
(\%)\end{array}\end{array}$ & $\begin{array}{c}\text { Light-[350-50] } \\
\mathrm{n}(\%)\end{array}$ & $\begin{array}{c}\text { Moderate - } \\
\text { [200-350] n (\%) }\end{array}$ & $\begin{array}{c}\text { Severe- <200 } \\
\mathrm{n}(\%)\end{array}$ & $\begin{array}{c}\text { Total } \mathrm{n} \\
(\%)\end{array}$ \\
\hline $\begin{array}{c}\text { With } \\
\text { dermatosis }\end{array}$ & $68(36.4)$ & $26(13.9)$ & $11(5.9)$ & $9(4.8)$ & $\begin{array}{c}114 \\
(61)\end{array}$ \\
\hline $\begin{array}{c}\text { Without } \\
\text { dermatosiis }\end{array}$ & $47(25.1)$ & $11(5.9)$ & $11(5.9)$ & $4(2.1)$ & $73(39)$ \\
\hline Total & $115(61.5)$ & $37(19.8)$ & $22(11.8)$ & $13(6.9)$ & $\begin{array}{c}187 \\
(100)\end{array}$ \\
\hline
\end{tabular}

$0.1 \leq p \leq 0.7$
We have diagnosed 240 dermatoses presented in Table 2 as infectious dermatoses (55 cases, 22.9\%) and non-infectious dermatoses (185 cases, $77.1 \%$ ). At least two dermatoses were observed in $97.4 \%$ of the infants. The 240 identified dermatoses were distributed according to the diagnostic and prognostic interest in common (65.5\%) opportunistic $(26.6 \%)$ and iatrogenic patients represented by drugs eruptions (7.9\%). Prurigo (19.2\%), oral candidiasis $(3.3 \%)$, tinea capitis $(2.5 \%)$, herpes simplex infection $(1.2 \%)$ and oral hairy leukoplakia (0.4\%) represented opportunistic dermatoses. We have not noticed tumoraldermatosis.

Immunosuppression was considered to be absent or mild (CD4 $\geq 350 / \mathrm{ml}$ ) in $82.5 \%$ of children with dermatosis and moderate to severe $(\mathrm{CD} 4<350 / \mathrm{ml})$ in $17.5 \%$. The immunologic profile according to the different types of infectious dermatoses and the two subgroups (infectious and non-infectious dermatoses) is illustrated in Table 3. There was no relationship between the degree of immunosuppression and the different types of infectious dermatoses, on the one hand and between the two subgroups of dermatoses $(0.2 \leq p \leq 0.6)$ on the other hand.

\section{Therapeutic data}

Of the 114 children consulted for dermatosis, 86 (75.4\%) were on ARV therapy and $28(24.6 \%)$ were not $p=0.3$. ARV therapy did not appear to prevent the development of dermatosis in HIV-infected children.

Table 2: Dermatoses observed in the 114 HIV-infected children seen in consultation in the SPGM from February to July 2016.

\begin{tabular}{|c|c|c|c|c|}
\hline \multicolumn{3}{|c|}{ Dermatosis (n; \%) } & \multirow{2}{*}{$\begin{array}{c}\begin{array}{c}\text { Number } \\
\text { of cases }\end{array} \\
9\end{array}$} & \multirow{2}{*}{$\begin{array}{c}\text { Proportion } \\
\%\left(^{*}\right)\end{array}$} \\
\hline \multirow{13}{*}{$\begin{array}{l}\text { Infectious (55 } \\
\text { cases; } 22.9 \% \text { ) }\end{array}$} & \multirow{5}{*}{$\begin{array}{c}\text { Fungal (23 } \\
\text { cases) }\end{array}$} & Pityriasis versicolor & & \\
\hline & & Oral candidiasis & 8 & 7.2 \\
\hline & & Tineacapitis & 6 & 5.3 \\
\hline & & Plane warts & 7 & 6.1 \\
\hline & & Chickenpox & 4 & 3.5 \\
\hline & \multirow{4}{*}{$\begin{array}{l}\text { Viral (17 } \\
\text { cases) }\end{array}$} & Herpes simplex & 3 & 2.6 \\
\hline & & $\mathrm{OHL}$ & 1 & 0.9 \\
\hline & & PPG & 1 & 0.9 \\
\hline & & Measles & 1 & 0.9 \\
\hline & \multirow{3}{*}{$\begin{array}{c}\text { Bacterial (12 } \\
\text { cases) }\end{array}$} & Boil & 5 & 4.4 \\
\hline & & Impetigo & 4 & 3.5 \\
\hline & & Superficial folliculitis & 3 & 2.6 \\
\hline & $\begin{array}{c}\text { Parasitic (3 } \\
\text { cases) }\end{array}$ & Scabies & 3 & 2.6 \\
\hline \multirow{11}{*}{$\begin{array}{c}\text { Non-infectious } \\
\text { (185 cases; } \\
77.1 \%)\end{array}$} & & Prurigo & 46 & 40.3 \\
\hline & & Xerosis & 45 & 39.5 \\
\hline & & Sweat dermatitis & 27 & 23.7 \\
\hline & & Eczema & 24 & 21.1 \\
\hline & & Drugseruptions & 19 & 16.7 \\
\hline & & Seborrhoeicdermatitis & 7 & 6.1 \\
\hline & & Psoriasis & 6 & 5.3 \\
\hline & & Juvenileacne & 5 & 4.4 \\
\hline & & Dermatosis/ SAM & 3 & 2.6 \\
\hline & & Follicularkeratosis & 2 & 1.8 \\
\hline & & Folliculareczematide & 1 & 0.9 \\
\hline Total & & & 240 & \\
\hline
\end{tabular}

NB $\left(^{*}\right)$ : Number of cases in relation to the number of children with dermatosis (114); SAM: Severe Acute Malnutrition; OHL: Oral Hairy Leucoplakia; PPG: Pinkish Pityriasis of Gibert 
Citation: Adegbidi H, Degboe B, Akpadjan F, Akioh I, Atadokpede F, et al. Skin Diseases in Human Immunodeficiency Virus-infected children in the era of Highly Active Antiretroviral Therapy: Epidemiological and Clinical Profile in Pediatric Department of Cotonou, Benin. J Clin Investigat Dermatol. 2017;5(2): 5

ISSN: 2373-1044

Table 3: Different groups of dermatoses according to the degree of immunosuppression in the 114 HIV-infected children seen in consultation in the SPGM from February to July 2016.

\begin{tabular}{|c|c|c|c|c|c|}
\hline \multicolumn{6}{|c|}{ Degree of immunosuppression - Number of CD4/ml } \\
\hline Dermatosis & $\begin{array}{c}\text { None } \\
-\geq 500 \mathrm{n} \\
(\%)\end{array}$ & $\begin{array}{l}\text { Light- } \\
{[350-500] \text { n (\%) }}\end{array}$ & $\begin{array}{c}\text { Moderate- } \\
{[200-350] \text { n (\%) }}\end{array}$ & $\begin{array}{c}\text { Severe - } \\
<200 \text { n (\%) }\end{array}$ & $\begin{array}{l}\text { Total } \\
\text { n (\%) }\end{array}$ \\
\hline Fungal & $15(65.2)$ & $3(13)$ & $2(8.7)$ & $3(13)$ & $\begin{array}{c}23 \\
(100)\end{array}$ \\
\hline Viral & $7(41.2)$ & $8(47)$ & $1(5.9)$ & $1(5.9)$ & $\begin{array}{c}17 \\
(100)\end{array}$ \\
\hline Bacterial & $6(50)$ & $3(25)$ & $0(0)$ & $3(25)$ & $\begin{array}{c}12 \\
(100)\end{array}$ \\
\hline Parasitic & $2(66.7)$ & $1(33.3)$ & $0(0)$ & $0(0)$ & $\begin{array}{c}3 \\
(100)\end{array}$ \\
\hline $\begin{array}{c}\text { Sub- } \\
\text { totalinfectious }\end{array}$ & $30(54.5)$ & $15(27.3)$ & $3(5.4)$ & $7(12.7)$ & $\begin{array}{c}55 \\
(100)\end{array}$ \\
\hline $\begin{array}{c}\text { Non- } \\
\text { infectious }\end{array}$ & $111(60)$ & $40(21.6)$ & $21(11.4)$ & $13(7)$ & $\begin{array}{c}185 \\
(100)\end{array}$ \\
\hline $\begin{array}{c}\text { Total } \\
\text { dermatosis }\end{array}$ & $141(58.7)$ & 55 (22.9) & $24(10)$ & $20(8.3)$ & $\begin{array}{c}240 \\
(100)\end{array}$ \\
\hline
\end{tabular}

Of the 86 children with dermatosis and treated, $75(87.4 \%)$ developed dermatosis after the initiation of ARV therapy and 11 (12.6\%) presented it before. The distribution according to the duration of the ARV treatment in 75 children who developed the dermatosis after the ARV was made in 3 subgroups: A1 ( $<6$ months), A2 (6-24 months), and A3 (> 24 month). The proportion in each subgroup was A1 (45 cases, $60 \%)$, A2 (18 cases, $24 \%)$ and A3 (12 cases, $16 \%$ ). The comparison between these 3 subgroups according to the duration of the treatment gave $0.46 \leq p \leq 0.95$. There was no significant difference in occurrence between children under ARV treatment of less than 6 months and those receiving ARV therapy of more than 6 months.

Therapeutic protocols are three types: X (2 NRTI + 1 NNRTI), Y (2 NRTI + $1 \mathrm{IP})$ and Z (3 NRTI). NRTI = nucleoside reverse transcriptase inhibitor, NNRTI = non-nucleoside reverse transcriptase inhibitor, IP $=$ protease inhibitor. The occurrence of dermatoses according to the therapeutic protocol in the 86 children was distributed as follows: $\mathrm{X}(90.7 \%), \mathrm{Y}(7 \%)$ and Z (2.3\%) $0.46 \leq \mathrm{p} \leq 0.95$. No protocol appeared to be higher in preventing the occurrence of dermatosis.

Cotrimoxazoleantibioprophylaxis was prescribed in $9.5 \%$ of children with dermatosis and $90.5 \%$ of children did not; $(\mathrm{p}=0.22)$. The administration of cotrimoxazole to children did not appear to influence the occurrence of dermatoses.

The frequency of prurigo in children on ARV was $23 \%$ compared with $44 \%$ in those without ARV, $\mathrm{p}=0.03$. The proportion of sweat dermatitis was $24.5 \%$ in children on ARV versus $21.4 \%$ in children without ARV $(p=0.004)$. The frequency of other dermatoses was not meaningfully different in children on ARV and in those without ARV $(\mathrm{p}>0.05)$

\section{Discussion}

\section{Epidemiological profile}

Dermatoses were common (61\%) in HIV-infected children and examinedat the University Hospital of Cotonou. Still, this occurrence is lower than in other African countries: 70.6\% (Zambia), 72.6\% and 79\% (Ethiopia) and 85\% (Tanzania) [3-6]. This occurrence was not related to sex $(\mathrm{p}=0.2)$ but appeared to be correlated with age as children under 4 years old were particularly affected $(\mathrm{p}=0.003)$. Children aged 0-5 years represent a vulnerable group due to the immaturity of their immune systems [10].

The majority of children in our series were of school age but only $2 / 3$ were really at school. Furthermore most of these children's mothers had a low educational level and had a low income source. These socio-economic factors could contribute to the high prevalence of dermatoses in these children through malnutrition and poor hygiene.

\section{Immunologic and clinical characteristics}

In most studies the occurrence and severity of dermatoses is proportional to the degree of immunosuppression. Thus a severe deficit is characterized by greater severity and frequency/multiplicity of dermatoses, particularly infectious and/or opportunistic ones. Still the frequency of dermatoses is already significant at an early stage of the disease (nul to mild immunosuppression). According to some authors, it varies between 20 and $71 \%$ in children with or without ARV treatment [2-9].

In our study, dermatoses occurred in the majority of cases $(84.2 \%)$ in stage 1 and 2 of the WHO and $82.5 \%$ of them had a null to mild immunodeficiency (CD4 $\geq 350 / \mathrm{Ml}$ ). Most dermatoses were noninfectious $(77.1 \%)$ and/or common (65.5\%) inflammatory. Although frequent, these mostly inflammatory dermatoses did not demonstrate advanced immunosuppression. This was strengthened by the fact that the presence or absence of dermatosis and the different types of dermatoses did not depend on the degree of immunosuppression ( $\mathrm{p}$ $>0.05$ ) (Tables 1 and 3 ).

Moreover, in the course of HIV infection some dermatoses, such as minor infections particularly common in children are not linked to cellular deficit but rather to a humoral deficit that can precede true cellular deficit [10].

The previous findings lead us to conclude that in addition to the immunosuppression defined by the WHO clinical stages and the CD4 there are other factors involved in the amplified prevalence of dermatoses in HIV-infected children. Mubiana-Mbewe and al and Ylitano $\mathrm{N}$ and al have shown that factors of vulnerability and co-morbidities such as age ( $<5$ years) malnutrition absence of cotrimoxazole prophylaxis late diagnosis of HIV infection or late onset of ARV therapy the type of ARV treatment was associated with a higher incidence of dermatoses in HIV-infected children $[3,15]$.

In addition, several authors observe a declineof certain vitamins in blood and trace elements such as selenium, zinc or copper in HIVinfected patients. This decline would be tributary to the oxidative stress induced by HIV during cellular activation in favor of its replication and on the other hand to the multifactorial malnutrition particularly frequent in countries with limited resources. These are important micronutrients involved in functional immune reconstitution. Their deficiency would therefore contribute to the worsening of the quantitative and qualitative deficit immunity [17-23].

Moreover akinboro and al in a recent study in Nigeria found that low blood levels of selenium were correlated with a higher occurrence of dermatoses, particularly prurigo, xerosis and oral candidiasis in 
Citation: Adegbidi H, Degboe B, Akpadjan F, Akioh I, Atadokpede F, et al. Skin Diseases in Human Immunodeficiency Virus-infected children in the era of Highly Active Antiretroviral Therapy: Epidemiological and Clinical Profile in Pediatric Department of Cotonou, Benin. J Clin Investigat Dermatol. 2017;5(2): 5

HIV-infected patients [19]. Shivakoti et al. have shown through a study in 9 countries that the deficiency of these vitamins and trace elements are not corrected by ARV treatment [23]. Baum and al in 2013 and Kamwesiga et al. in 2016 have shown in large cohorts of HIV-positive patients that supplementation with vitamins and trace elements contributes to improving immunity and significantly reducing morbidity associated with HIV infection [20,21].

Opportunistic dermatoses counted for about a quarter of the total and included prurigo (Figure 1), oral candidiasis, tinea capitis, herpes and hairy oral leukoplakia. In children these opportunistic conditions occur earlier in a mild to moderate stage of deficit, as compared to adults [10].

The prurigo identified in $40.3 \%$ of the children of our series was the most frequent dermatosis. This high prevalence may be related to our type of study. Indeed, the majority of children had certainly developed prurigo before our investigation. This hypothesis is confirmed on the one hand by the chronic characteristic with capricious evolution of this affection and on the other hand by the presence of an antecedent of prurigo in $38.7 \%$ of these children. Prurigo is the result of chronic pruritus. Its likely multifactorial etiology remains controversial. Yet, the probe for a general cause (lymphoma or helminthiasis) must be systematic $[2-6,10]$

According to WHO estimates in December 2005, 2.3 millions children are living with HIV, 2.1 millions of them in sub-Saharan Africa [1]. In tropical areas, prurigo is a good marker of HIV infection both for health workers and for the general population. There remains a chronic dermatosis, displaying and very unsightly on dark skin. This often obliges these children to live beyond the test of HIV infection the social stigmatization of prurigo. Despite the therapeutic advances, HIV-infected children represent a psychological vulnerability justifying multidisciplinary care in order to accompany them as best they can in their adult life. Xerosis (39.5\%), sweat dermatitis (23.7\%), eczema $(21.1 \%)$ and drugs eruptions $(16.7 \%)$ were among the most frequent dermatoses after prurigo.

The occurrence of eczema during HIV infection is unknown but appears to be high especially in children. In our series, more than one in five children were affected. Chronic skin dry is the primary trigger [10]. Additional studies should be considered to determine the clinical and etiological characteristics of eczema in this area.

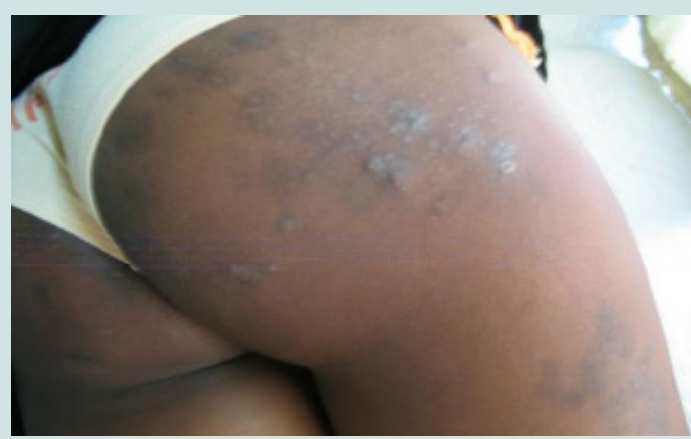

Figure 1: Prurigo in an HIV-infected girl.
Xerosis particularly common in HIV-positive and atopic patients would be aggravated by some ARVs such as anti-proteases and immune deficiency. It is a major cause of chronic pruritus. It is involved in the pathogenesis of prurigo and eczema. A causal relationship could be the cause of the high frequency of these three conditions $[10,24]$.

The occurrence of sweat dermatitis may be related to its seasonality. Drugs eruptions although frequent did not threaten the vital prognosis (Figure 2). They are mainly caused by ARV and antibioprophylaxis by cotrimoxazole [10].

Almost all children (94.7\%) had at least two dermatoses. This multiple character has been confirmed by most previous studies [29]. It could be due to the deficiency in vitamins and trace elements pointed out previously. Common dermatoses suspecting HIV infection are known to be trailing, atypical or resistant to treatment $[10,25]$. The multiple nature of dermatoses could be rightly considered as a specificity leading to HIV infection in children.

In Benin a prevalence of $3.2 \%$ of Kaposi's disease in adults has been reported [26]. Like most previous pediatric studies which found rarely or no cases of tumor dermatosis such as Kaposi's disease we have not observed such cases. This observation may also be related to the short duration of our study which did not allow us to receive cases of infantile Kaposi's disease [5,9,19].

\section{Frequency of dermatoses and therapeutic strategies}

Therapeutically $75.4 \%$ of children were on ARV. ARV treatment did not seem to influence the overall frequency of dermatoses $(\mathrm{p}=$ 0.3 ). Our results are superimposable on those of Endayehu and al in Ethiopia and Panya and al in Tanzania [4-5].

Therapeutic protocols included three ARVs and were therefore highly active. Almost all (90.7\%) were under protocol X (2 NRTI + 1 NNRTI). This fact correlates with good immune status of the majority of children which indicated the efficiency of therapeutic strategies and monitoring of these children regarding immunosuppression. However HAART, whatever the established protocol did not appear to significantly reduce the overall frequency of dermatitis $(\mathrm{p}>0.05)$.

Cotrimoxazole antibiotic prophylaxis was only effective in $9.5 \%$ of these children. This may be related to the more limited indications of antibiotic prophylaxis in children. Still it did not seem to influence the occurrence of dermatoses $(\mathrm{p}=0.22)$.

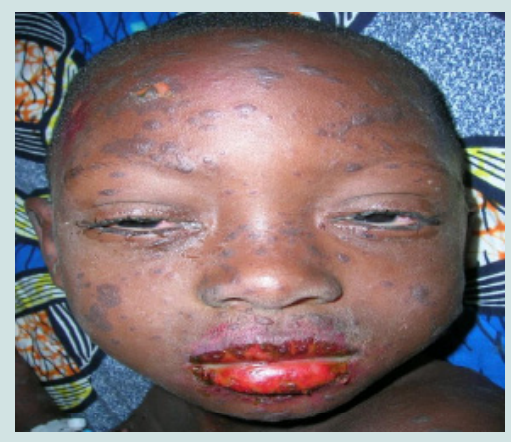

Figure 2: Drug eruption in an HIV-infected boy. 
Citation: Adegbidi H, Degboe B, Akpadjan F, Akioh I, Atadokpede F, et al. Skin Diseases in Human Immunodeficiency Virus-infected children in the era of Highly Active Antiretroviral Therapy: Epidemiological and Clinical Profile in Pediatric Department of Cotonou, Benin. J Clin Investigat Dermatol. 2017;5(2): 5

Precisely the impact of HAART was positive on the occurrence of prurigo with a lower prevalence statistically significant in children on ARV $23 \%$ versus $44 \%$ of children without ARV. The reverse phenomenon was observed significantly with sweat dermatitis and not significant with other dermatosis. From these observations we can suggest that the higher prevalence of sweat dermatitis despite seasonality in patients on ARV approaches the phenomenon observed with the increase in the frequency of drugs eruptions and xerosis on ARV. This suggests a role of susceptibility linked to the ARV treatment in the appearance of the sweat dermatitis. The existence of other factors of vulnerability and comorbidity above-mentioned confirmed the absence of any significant impact of ARV treatment on the occurrence of other dermatoses.

\section{Conclusion}

Fourteen years after the introduction of ART combination therapy in the Pediatric and medical Genetics Department at the University Hospital of Cotonou, dermatoses were frequent multiple but not severe in HIV-infected children. They were dominated by non-infectious common inflammatory dermatoses.According to our results these treatments had three important positive impacts: first the improvement of HIV-induced immunodeficiency, secondly the marked reduction in the severity of dermatoses whether opportunistic or not thirdly the marked decrease in the occurrence of infectious and opportunistic dermatoses. Yet they did not contribute to reducing the overall frequency of dermatoses and their multiple character.

We conclude that immunosuppression contributes to the severity of dermatoses in HIV-infected children. However, the improvement of immunity under HAART alone, is not sufficient to reduce the occurrence and / or multiplicity of dermatoses. This suggests the existence of other factors of vulnerability and co-morbidity to be sought in order to improve the quality of life of HIV-infected patients and particularly in children.

\section{References}

1. Gottschalk GM (2006) Pediatric HIVIAIDS and the skin: An update. Dermatol Clin 24: 531-536.

2. Umoru D, Oviawe O, Ibadin M, Onunu A, Esene H (2012) Mucocutaneous manifestations of pediatric human immunodeficiency virus/acquired immunodeficiency syndrome (HIVIAIDS) in relation to degree of immunosuppression: A study of a West African population. Int J Dermatol 51: 305-312.

3. Mubiana-Mbewe M, Bolton-Moore C, Banda $\mathrm{Y}$, Chintu $\mathrm{N}$, NalubambaPhiri M, et al. (2009) Causes of morbidity among HIV-infected children on antiretroviral therapy in primary care facilities in Lusaka, Zambia. Trop Med Int Health 14: 1190-1198.

4. Endayehu Y, Mekasha A, Daba F (2013) The pattern of mucocutaneous disorders in HIV infected children attending care and treatment in tikur anbesa specialized hospital, Addis Ababa, Ethiopia. BMC Dermatol 13: pp. 12.

5. Panya MF, Mgonda YM, Massaye AW (2009) The pattern of mucutaneous disorders in HIV-infected children attending care and treatment centres in dar es salaam, Tanzanie. BMC Public Health 9: pp. 234.

6. Doni SN, Mitchell AL, Bogale Y, Walker SL (2011) Skin disorders affecting human immunodeficiency virus-infected children living in an orphanage in Ethiopia. Clin Exp Dermatol 37: 15-19.

7. Oliveira de Carvalho V, Marinoni LP, Martins LT, Giraldi S, Taniguchi K, et al (2003) Dermatologic alterations in children with AIDS and their relation with clinical-immunological categories and viral load. An Bras Dermatol Vol. 78.
8. Wananukul S, Deekajorndech $\mathrm{T}$, Panchareon $\mathrm{C}$, Thisyakorn U (2003) Mucocutaneous findings in pediatric AIDS related to degree of immunosuppression. Pediatr Dermatol 20: 289-294.

9. El Hachem M, Bernardi S, Pianosi G, Krzysztofiak A, Livadiotti S, et al. (1998) Mucocutaneous manifestations in children with HIV infection and AIDS. Pediatr Dermatol 15: 429-434

10. Maurer TA (2005) Dermatologic manifestations of HIV infection. Top HIV Med 13: $149-154$.

11. Seoane Reula E, Bellon JM, Gurbindo D, Muñoz-Fernandez MA (2005) Role of antiretroviral therapies in mucocutaneous manifestations in HIV-infected children over a period of two decades. Br J Dermatol 153: 382-389.

12. Gona P, Van Dyke RB, Williams PL, Dankner WM, Chernoff MC, et al. (2006) Incidence of opportunistic and other infections in HIV-infected children in the HAART era. JAMA 296: 292-300.

13. Dunic I, Vesic S, Jevtovic DJ (2004) Oral candidiasis and seborrheic dermatitis in HIV-infected patients on highly active antiretroviral therapy. HIV Med 5: 50-54.

14. Levin MJ, Anderson JP, Seage GR $3^{\text {rd }}$, Williams PL (2009) Short-term and long-term effects of highly active antiretroviral therapy on the incidence of herpes zoster in HIV-infected children. J Acquir Immune Defic Syndr 50: 182191

15. Ylitalo N, Brogly S, Hughes MD, Nachman S, Dankner W, et al. (2006) Risk factors for opportunistic illnesses in children with human immunodeficiency virus in the era of highly active antiretroviral therapy. Arch Pediatr Adolesc Med 160: 778-787.

16. Puthanakit T, Aurpibul L, Oberdorfer P, Akarathum N, Kanjananit S, et al. (2007) Hospitalization and mortality among HIV-infected children after receiving highly active antiretroviral therapy. Clin Infect Dis 44: 599-604.

17. Stone CA, Kawai K, Kupka R, Fawzi WW (2010) Role of selenium in HIV infection. Nutr Rev 68: 671-681.

18. Patrick L (1999) Nutrients and HIV: Part one - beta carotene and selenium. Altern Med Rev 4: 403-413

19. Akinboro AO, Mejiuni DA, Onayemi O, Ayodele OE, Atiba AS, et al (2013) Serum selenium and skin diseases among Nigerians with human immunodeficiency virus/acquired immune deficiency syndrome. HIV AIDS (Auckl) 5: 215-221.

20. Baum MK, Campa A, Lai S, Sales Martinez S, Tsalaile L, et al. (2013) Effect of micronutrient supplementation on disease progression in asymptomatic, antiretroviral-naive, HIV-infected adults in Botswana: A randomized clinical trial. JAMA 310: 2154-2163

21. Kamwesiga J, Mutabazi V, Kayumba J, Tayari JC, Uwimbabazi JC, et al. (2015) Effect of selenium supplementation on CD4+ T-cell recovery, viral suppression and morbidity of HIV-infected patients in rwanda: A randomized controlled trial AIDS 29: 1045-1052.

22. Doddigarla Z, Bhaskar MV, Lingidi JL, Ashraf R (2013) Evaluation of zinc, copper and oxidative stress in HIV seropositive cases. HIV AIDS Rev 12 79- 81

23. Shivakoti R, Christian P, Yang WT, Gupte N, Mwelase N, et al. (2016) Prevalence and risk factors of micronutrient deficiencies pre- and postantiretroviral therapy (ART) among a diverse multicountry cohort of HIVinfected adults. Clin Nutr 35: 183-189.

24. Lee D, Benson CA, Lewis CE, Grunfeld C, Scherzer R (2007) Prevalence and factors associated with dry skin in HIV infection: The FRAM study. AIDS 21: $2051-2057$

25. Rennert WP (2005) Infectious cutaneous manifestations of HIV infection in children. AIDS Read 15: 619-622.

26. Atadokpede F, Yedomon $\mathrm{H}$, Adegbidi H, Sehonou JJ, Azondekon A, et al (2008) Mucocutaneous manifestations of human immunodeficiency virus infection in Cotonou, Benin. Med Trop (Mars) 68: 273-276. 